\title{
Libraries of Nazarbayev Intellectual Schools: School Library as an Integrated Information and Educational Space of the Modern School
}

\author{
Aida Agadil \\ agadila@nis.edu.kz
}

Nazarbayev Intellectual Schools, Kazakhstan.

Rauan Yessenbek

esenbekr@fmsh.nis.edu.kz

Nazarbayev Intellectual School of Physics and Mathematics in Shymkent, Kazakhstan.

\section{Sandugash Dospayeva}

dospayeva_s@,tk.nis.edu.kz

Nazarbayev Intellectual School of Physics and Mathematics in Taldykorgan, Kazakhstan.

Keywords: Kazakhstan, Nazarbayev Intellectual School, NIS, reading, teacher-librarian, library activities, school library role, reading games, promotion of reading.

\begin{abstract}
Nazarbayev Intellectual Schools (NIS) are established to become an experimental platform that develops, monitors, studies, analyzes, tests, and implements modern models of educational programs by levels. Accordingly, as an important part of the school, one of the main goals of NIS libraries is to comply with international standards of school libraries, to improve professional qualifications, to facilitate the implementation of the mission and objectives of the school. For this, it is necessary to shift away from traditional methods and established stereotypes and raise libraries to the modern international level. This article offers an introduction to working methods of the libraries of the Intellectual Schools, which include developing students' reading skills, use of games to motivate students to read, the development of critical thinking skills of students.

NIS librarians use game methods, festivals and activities to promote reading among students, which enables the teacher-librarians to raise children's confidence and gain pleasure from reading, discover reading choices, provide children with opportunities to share their reading experience and to raise the status of reading as a creative activity. There are also various library projects, clubs and actions, which motivate students to read and instill in students the love of reading.

The libraries provide students with resources for learning and reading. They are welcoming and flexible, reader-friendly environments including different zones for research, independent and collaborative work with colours, materials and layout designed to provide safe and accessible places conducive to learning and reading.
\end{abstract}


Promotion of books and reading is the main direction in the activity of each library. Programs for the promotion of books and reading are implemented with the involvement of all categories of users at the libraries of Nazarbayev Intellectual schools. Students reading development is a system of interrelated projects, actions and games aimed at developing reading competence, developing students' skills of critical thinking, information and functional literacy, and reading activity. Teacher-librarians of NIS use various projects and gamification to promote the development of interest in fiction, the formation of literary taste, cultivation of the need to communicate with the book, and bringing students closer to the best and worthy of books, creating a community of people united by the common idea of promoting reading. So what is gamification? "Gamification in libraries is the use of elements of games to engage readers with libraries. Every gamified system has to be designed to achieve a goal. In the case of libraries, gamification will be in line with their own objectives, promote reading, train in the tools of access to the information and improve communication channels to spread their services" (Engaging library visitors through gamification, n.d.).

The advantages of gamification are:

- promotion of spatial reasoning, math and logic

- building awareness and reflective thinking

- asking questions and processing what is being learned through play

- improvement of players' social skills

- the sensation of excitement and joy

- the emotions of wonder and curiosity from the discovery of a new world that the game presents

- the challenge that tests our abilities and boosts our confidence, or the chance to release stress and worries.

Teacher-librarians of NIS use various games and quests in their activity. The quest called "Wandering" requires the accomplishment of some tasks with the aim of proceeding to different stages of the quest. While doing such quests as "Wandering" students get to know the classification and services of the library better for the reason that the tasks of the quest are linked to the building and the territory of the library. They also improve their knowledge of authors and their works developing their erudition and demonstrating their resourcefulness. Moreover, the tasks of the quest meet the needs of students in developing their competitiveness, pursuit of success and social skills. The tasks that teacher-librarians of NIS use in the quests include creative, erudite, sporty, combined or navigational ones. The prompts for students are given in the form of pages of books on the bookshelves, on the internet, on the special book-exhibition or special files and presentations on computers of the library. Teacher-librarians control students by summing up their points and finish the quest by checking the first group or a student who completed all the tasks correctly or stopping the quest if the students run out of time. There can also be nominations for winners and penalties for non-fulfilment of tasks, violation of the route. The penalties may be in the form of additional tasks and questions. NIS teacher-librarians organized a quest on the theme of "Greek Gods". Students were asked to find cubes with questions on each side of them using clues and answer as many questions as they can. The groups of students got points and the winners were announced and awarded sweet prizes.

Apart from games and quests teacher-librarians organize festivals. One of them is the festival of "Edible books". The goals and objectives of the festival are:

- increasing prestige and promotion of reading by organizing extracurricular activities

International Association of School Librarianship

https://iasl-online.org 
achieving positive changes in the formation of students' reading literacy, as well as involving parents in the school community and combining the efforts of the library and curatorial service of the school in developing students' reading culture.

Participants from each shanyrak ("shanyraks" are groups of students from different grades working together on projects and extracurricular activities) take part in the festival with great interest. According to the rules of the festival, students choose and read the selected book. Within the framework of the festival program, students and parents introduce an exhibition-fair of "edible" book-cakes, where the book cover, characters, plot, objects from a work, etc. are presented. One of the conditions is the production of an "edible" book by participants at the venue of the festival from confectionery semi-finished products, pre-made parts of a cake and colorful interesting designs.

The participants also present the selected "edible book" in the book genre, stage the most famous and favorite episodes of their favorite books in the costumes of the heroes of the works.

The festival jury evaluates the work of each creative group, determines the winners in creative categories and the absolute winners in different nominations such as: "The patriot book", "The Nobel laureate book", "The bestseller book", “The fantasy book", "The adventure book."

This unusual and creative event undoubtedly contributes to the further increase of students' interest in reading and the development of their creative abilities.

NIS teacher-librarians also use activities such as "Reading Man". It is a book event where the teacher and the student become closer to each other. On the day of the event, students who come to the library for books are handed out a sheet of paper with tasks. After receiving the sheet, the student is sent to the teacher indicated in this sheet, and performs the task. The tasks usually make students do something unusual and interesting. After completing the assignment, the student receives the teacher's signature, returns and can select a gift in turn. The goal of the activity is to increase the level of confidence in the librarian, interest in the library, the establishment of communication between teachers and school administration.

Through gaming elements, NIS libraries enhance the user experience by giving students meaningful, satisfying work and catering for their learning styles and information-seeking behaviors. Games and gamification, festivals have the potential to improve student engagement and significantly increase positive learning.

1. Engaging library visitors through gamification. Retrieved from https://princh.com/engaging-library-visitors-through-gamification-interview-ana-ordas/\#.XXPdw $\underline{\mathrm{vAzbcs}}$ 